\title{
Lacanismo y retórica en dos manifestaciones de lo Real en la poesía peruana de la violencia: Alejandro Romualdo y Pablo Guevara
}

Lacanism and retorics in two expressions of the Real in peruvian poetry from the politic violence years: Alejandro Romualdo y Pablo Guevara

\author{
Carlos Manuel Arámbulo López \\ Universidad Científica del Sur, Lima, Perú \\ Contacto: carambulo@cientifica.edu.pe \\ https://orcid.org/0000-0002-4970-3765
}

\begin{abstract}
Resumen
El presente trabajo enfrenta la lectura de dos conjuntos de poemas que desarrollan el tópico de las desapariciones durante las décadas de 1980 y 1990 - A los ataúdes, a los ataúdes de Pablo Guevara (1999) y Ni pan ni circo de Alejandro Romualdo (2005) - como manifestaciones del enfrentamiento con lo real; ello desde decisiones opuestas, tanto en el ámbito de los cinco componentes de la retórica clásica como en cuanto al intellectio, operación propuesta como preeminente en el procedimiento de simbolización para la producción de textos literarios. La lectura propuesta es un intento de aproximar la perspectiva del psicoanálisis textual lacaniano a los postulados de la retórica general textual como la entiende Stefano Arduini.

Palabras claves: Poesía peruana; Violencia política; Alejandro Romualdo; Pablo Guevara; Retórica general textual; Lacanismo; Lo Real.
\end{abstract}

\begin{abstract}
This study approaches two books of poems dealing with the disappeared during the terror years in Perú (1980-1990), "A los ataúdes, a los ataúdes" from Pablo Guevara (1999) and "Ni pan ni circo" from Alejandro Romualdo (2005). Both authors deal with an image on the Real following different approaches to the five components of classic rhetoric and also to the "intellection" as symbolizing procedure for literary creation. The proposal intends to close the gap between lacanian texts psychoanalysis and General textual rhetoric following Stefano Arduini.
\end{abstract}

Keywords: Peruvian poetry; Political violence; Alejandro Romualdo; Pablo Guevara; General textual rhetoric; Lacanism; The Real.

Recibido: 03.06.18

Aceptado: 30.10 .18 
La poesía de la "década violenta" (1980-1990) ha conocido diferentes realizaciones, algunas más logradas que otras respecto al valor estético de las mismas, valoración siempre subjetiva y discutible. Entre las dos más notables se cuentan A los ataúdes, a los ataúdes de Pablo Guevara (1999) y Ni pan ni circo de Alejandro Romualdo (2005) ${ }^{1}$.

El poemario de Guevara se incluye en una obra de aliento mayor que el autor publicó luego de un silencio literario que duró casi treinta años, La colisión, que subtituló Obra marítima en cinco actos e incluye Un iceberg llamado poesía; En el bosque de hielos; A los ataúdes, a los ataúdes; Cariátides y Quadernas, quadernas, quadernas. Señala Higgins (2006: 260) que a partir de la metaforización del hundimiento del Titanic, Guevara construye una representación de la crisis de la humanidad a lo largo del siglo XX. Es un trabajo de aliento poundiano, cercano a la intención que animó la redacción de los Cantos, y así debe leerse la inclusión de los sucesos de la violencia política como exemplum de la crisis humana mencionada por Higgins.

Alejandro Romualdo había construido una reputación sólida como logrado poeta "puro", para citar una distinción que no compartimos pero empleamos por difundida y común, cuando decidió hacer de lo social el componente principal de su obra por encima de lo introspectivo o contemplativo. Así como Guevara retorna a la publicación luego de casi treinta años, Romualdo revisita la dimensión lírica de su poesía, esta vez encontrando una síntesis afortunada con el acontecimiento social en Ni pan ni circo (2005). Recordemos que el rompimiento con su poética previa puede datarse en el año de aparición de Poesía concreta, 1952. A falta de treinta, este es un periodo de cincuenta y tres años.

Al leer juntos A los ataúdes, a los ataúdes y Ni pan ni circo, comprobamos que ambas propuestas se aproximan a lo Real (el sinsentido, la presencia de la muerte física) como referente, pero sus estrategias plantean diferencias importantes al nivel de lo imaginario y lo simbólico. Por imaginario entenderemos el mundo retratado, lo que incluye espacio, objetos y personajes; mientras que por simbólico, la articulación de lo imaginario en una red significativa cosida con el 
hilo de lo Real. En dicho sentido, es simbólico el personal manejo del lenguaje poético que se hace evidente en la construcción del verso y la reproducción en el sentido de la presencia de lo Real.

\section{La literatura como instancia de lo Real}

Entre el suceso y el lenguaje se constata un vacío, una inexistencia significativa que anuda el sentido hasta el extremo de generar la apariencia de despojarse de él. Es la representación del sinsentido, de lo Real. Creemos que todo texto porta sentido, incluso cuando afronta lo irrepresentable, lo inasible; asumir el sinsentido como trasfondo del acontecimiento supone caer en el irracionalismo, en el "porque sí" absoluto que da origen a la razón cínica tal como la define Stloterdijk (2011) $)^{2}$.

Entonces, la labor del arte es la contemplación del sinsentido desde la producción de un sentido o sentidos que se aproximen a eso que es irrepresentable. El lenguaje cotidiano elude esta confrontación, la literatura enfrenta el reto de acercar los dos extremos del abismo; por un lado, el hecho descarnado, por otro, su recreación condenada a la fragmentariedad, a la incompletitud. La naturaleza de la retórica se hace evidente en esta instancia. Su labor es la de intentar llenar el vacío con la reconstrucción de la vivencia. Si asumimos que el sentido atraviesa todo suceso, aunque no podamos discernirlo, debemos concordar en la existencia de sucesos ante los cuales este discernimiento se dificulta no solo por la conexión oculta entre el acontecimiento o suceso y su sustento, cual fuese su naturaleza, sino además por lo que podemos denominar "densidad" del suceso. Este encuentro con acontecimientos de densidad desmedida, al punto del agobio, se acerca a la experimentación de lo sublime o de lo absoluto, es una manifestación del goce.

Extendiendo nuestra reflexión, el goce es nuestra llave hacia lo absoluto, lo inefable, lo sublime. De las múltiples formas del goce que construye el ser humano, una de las más evidentes es el arte, y este reviste muchas máscaras. Cuando su materia es la palabra hecha texto estamos ante lo literario, la literatura, y el vehículo de la literatura para facilitar el acceso al goce se llama retórica. 
Somos capaces de leer las narraciones de sucesos atroces porque existe un vehículo que justifica nuestro acercamiento y lo vicariza, asume la carga de la culpa de observar nuevamente o de cerca lo indebido; aplaudimos textos por su logro literario sin detenernos en la justificación moral de su componente narrativo porque valoramos la discursividad y la retórica del mismo. De no ser así, algunas escenas de filmes de David Lynch, por ejemplo, nos serían intolerables. Pensemos en Mulholland Drive (Edelstein y Lynch, 2001) y la secuencia del descubrimiento del cadáver de la joven la protagonista en una casa a la que ingresa sin autorización, documentado con precisión e impudicia por una cámara que reemplaza a nuestra mirada mordaz. No queremos ver un cuerpo humano enfrentando los momentos más crudos de la descomposición, menos aún imaginarnos el propio en un morboso futuro, pero en la pantalla del cinema algo justifica nuestra permanencia en la sala. Es el mismo fenómeno que se observaba en las funciones de Saló, o los 120 días de Sodoma (Grimaldi y Pasolini, 1975), dirigida por Pier Paolo Pasolini: algunos pocos espectadores permanecían en la sala mientras la mayoría había ido abandonándola poco a poco.

El goce literario se independiza del suceso. No es condición pero puede ocurrir. Los sucesos sublimes vinculados a emociones reconocidas como "positivas" encuentran una cierta adecuación a su materia retorizada cuando, por ejemplo, oímos creaciones musicales vinculadas a la trascendencia, como es el caso de las rãgas hindúes, o la pintura religiosa del Quattrocento. Sostener el dolor, conocer el lado negativo de lo Real, supone un manejo del arte capaz de superar la materia o, al menos, justificar su tratamiento. Por supuesto, existen, además, razones ideológicas y políticas para sustentar y apoyar este exceso de labor retórica, las mismas que ayudan a soportar la carga de la inexpresabilidad a la que está condenada la literatura, porque es la constatación de ese vacío lo que constituye la huella de lo literario. Nada que podamos lograr desde la excelencia literaria podrá igualar la vivencia de quien "estuvo ahí".

Desde esta perspectiva leemos la aceptación del arte de denuncia, que permite acceder a lo condenable y se regodea en la reconstrucción de lo más 
penoso porque persigue un fin ulterior. Si recurrimos a las funciones del lenguaje formuladas por Jakobson (1981), la función apelativa sería la principal: el texto se propone generar una toma de posición. En este sentido es que podemos insertar el término "ideología". Esta condición genera la necesidad de lograr un sabio balance; lo literario y lo ideológico establecen la existencia de un continuo que lleva, en un extremo, el texto panfletario y, en otro, el olvido de la dimensión del acontecimiento y el distanciamiento respecto a lo Real. Lo paradójico en el caso de la literatura, y en los casos que nos ocupan, es la constatación de que aunque el distanciamiento es innegable y connatural al arte, el distanciamiento consciente respecto a él resta impacto al texto. La condena de la literatura es que sus objetos están forzados a abordar lo imposible bajo pena de perder el estatuto de texto literario.

Las formas de afrontar esta constatación de la imposibilidad varían entre autores y, para el caso que nos ocupa, hemos tomado como modelos dos textos acerca de los restos de la violencia en Ayacucho durante los años de la violencia política. La reconstrucción de lo imaginario marca las diferencias entre $A$ los ataúdes, a los ataúdes de Pablo Guevara (1999) y Ni pan ni circo de Alejandro Romualdo (2005). Las diversas aproximaciones de ambos autores, desde el nivel de la intellectio, operación que Stefano Arduini (2000) coloca en un nivel preeminente respecto a las cinco operaciones clásicas de la retórica ${ }^{3}$, expresan cómo una estrategia de contraste y otra de adecuación pueden ser funcionales en términos poéticos y articular, igualmente, textos de denuncia y vehículos de goce eficientes.

Sin esta operación preliminar no se explican las elecciones sobre el imaginario en ambos textos. Existe, así, como una operación preliminar que articula autor con campo literario y serie histórica a través de la creación de la estrategia retórica. Según Arduini:

En los términos con los que la hemos introducido, parece, pues, que la intellectio tenga que ver con las que son [sic] las relaciones entre mundo, cultura y lenguaje en cuanto a proporcionar los presupuestos al texto retórico, establece también las coordenadas en el interior de las cuales el mundo puede ser transferido al texto mismo. $\left(2000\right.$, p. 61) ${ }^{4}$ 
Por lo tanto, podemos derivar que, en los textos literarios como los que nos ocupan, la intellectio establece el vínculo de lo imaginario y lo simbólico con lo Real, permitiendo la articulación del discurso.

\section{Lo Real como articulador del discurso}

Siguiendo a Lacan sabemos que lo Real articula los restantes dos componentes del "nudo borromeo", es el elemento que otorga sentido al texto (Jameson, 1977), la interferencia o inclusión de la Historia del sujeto en la cadena significativa. Las manifestaciones de lo Real tanto en lo simbólico como en lo imaginario se pueden leer como síntoma, como aquello que se repite y en cuya reiteración asoma el fantasma de lo Real. Sobre lo fantasmático y lo imaginario en los textos de la violencia creemos que existe una discusión pendiente. El fantasma es una construcción que hace sostenible o tolerable la vivencia de lo real; es aquello que da la forma final al síntoma y permite construir una escena en la cual se articula el deseo. En los textos de la violencia, lo fantasmático se construye como un acercamiento a lo Real. En el resquicio entre goce y recreación formal, se instaura un elemento justificador; el texto busca exponer lo Real y para ello recurre a la creación de esa prima de placer que es la realización formal. Es en la generación de esta forma reconocible como literaria que se cuela lo Real. La forma literaria es el soporte de esa imagen fantasmal, la posibilidad de generar desde la perspectiva del goce una construcción textual que soporte lo real mediante la metaforización, principalmente, y demás figuras retóricas. Es el soporte literario, la literaturización de la vivencia, aquello que logra dar tolerabilidad desde la perspectiva del goce a lo Real sinsentido. Nos congratulamos por la eficacia discursiva, la riqueza de recursos y el manejo del repertorio vigente en el campo, aplaudimos osadas innovaciones sobre el trasfondo doloroso de una narratividad intolerable. Lo otro es documentalismo de campo de concentración, imágenes de cuerpos mutilados, fosas clandestinas abiertas e imaginería directa de lo histórico Real. En sentido contrario, los dos poemarios construyen una fantasmática: idílica uno y kafkiana (burocrática) el segundo, como mecanismos para desplazar la tensión en la tríada (imaginario-simbólico-real). En ambos casos se lee un evidente intento de acceder 
a la Historia tras el texto desde una elaboración discursiva soportada en la creación de un entorno, un ambiente físico. Por lo tanto, aunque lo Real sea aquello que escapa a la representación, no podemos afirmar que la representación evada el enfrentamiento con lo Real, aunque conozca de antemano la imposibilidad del logro. Pasaremos a revisar las divergencias desde el fondo común histórico, Real, de ambos textos.

\section{Las divergencias imaginarias: el espacio y los actores}

La primera divergencia corresponde al espacio representado, es decir, al escenario del texto. En el caso de los poemas de Romualdo, se trata de un espacio abierto, reconocible por referencias de entorno como la sierra del Perú; podría especificarse más diciendo Ayacucho:

Árboles, arroyos, cascadas

suspendidas

en un hilo de agua, música de fondo

en los abismos nevados y silencio

porque son trozos los que escuchan.

Se veían bandadas como mantos

que cubrían los cerros encendidos,

aves desconcertadas, sin destino,

y estampidos de terror en la lejanía. (Romualdo, 2005, p. 40)

Sobre el escenario idílico, pastoril, "los trozos", directa alusión al despedazamiento de los cuerpos y "los estampidos de terror en la lejanía", los cuerpos huyendo del peligro, insertan no solo su rol de actores, también introducen el elemento simbólico (la amenaza) que ancla el texto en la historia.

Por otro lado, el poemario de Guevara se escenifica en el espacio de la burocracia, la oficina, la dependencia policial o el ministerio. Una mirada se abre hacia el exterior, otra se cierra sobre el espacio de la desesperación kafkiana ante la indolencia del gran Otro. Su estrategia discursiva, a diferencia de aquella de Romualdo, consiste en sumergirse en la interacción, en la narratividad, de manera 
más directa mediante el uso de la apelación directa. Repite la experiencia clásica de la catarsis intentando que la apelación actúe en dos tiempos, el de la ejecución o performance real y el de la reconstrucción gozosa ${ }^{5}$, el momento en el cual el lector comparte la frustración y la rabia al sentirse tratado figurativamente como el doliente en busca de su difunto-desaparecido:

Vayan a otra Delegatura... Llenen este formularios pongan sus nombres y apellidos completos. Pongan su domicilio su teléfono que si hay novedad ya les avisaremos... (Guevara, 1999, p. 49)

Aunque esté detenido a pocos metros de usted paredes de por medio o al fondo del edificio en el subsuelo nadie le va a decir nadie le va a dar razón ni le van a dejar ver a usted un centímetro o un milímetro de su piel todavía existen porque son órdenes superiores de la superioridad no mostrar a nadie ningún detenido quien entra ya no sale vivo por ningún motivo... (Guevara, 1999, p. 41)

El actor del poemario de Romualdo es ambiguo, es un yo ausente; es el difunto, el desaparecido, el que ya no es o el no-viviente. El poemario de Romualdo alude al ausente por la marca sobre los otros, con o minúscula; no estamos enfrentados al gran Otro porque la elaboración fantasmática del texto lo ha excluido y solo lo leemos como el efecto de su paso, su presencia es mediatizada por sus mecanismos de recreación (delegaturas, comisarías, cuarteles, etc.), lo Real es irrepresentable.

De todo esto queda la tierra calcinada

y el pecho con latidos que no

$$
\text { comprenden }
$$

tanta sangre vertida, restos de

quimeras,

fragmentos que fueron todo y ahora

no evocan

ninguna plenitud. $\mathrm{Al}$ amanecer,

las puertas vencidas dan al

cementerio. (Romualdo, 2005, p. 50) 
En el poemario de Guevara el actor es el sobreviviente, el doliente ${ }^{6}$ en su enfrentamiento contra la in-dolencia del Otro (que esta vez sí está personificado) en el comisario, el dependiente, el empleado del Estado o el gran absurdo de convertir en no-existente (desparecido) lo que existió (hermano, esposo, hijo) y ahora es no-viviente (supuesto fallecido, $\mathrm{NN}$ ). La desaparición del cuerpo es el referente principal del texto de Guevara.

En el ocultamiento del paradero del desaparecido se manifiesta la obscenidad del poder del $\mathrm{Otro}^{7}$; es la exhibición de su dominio sobre el otro cuerpo y su capacidad para leerlo como un universal sin diferenciación, un inexistente salvo en cuanto logre actuar. En estos mismos términos, Badiou presenta la existencia del sujeto colectivo que llamamos "pueblo", que aparece y desaparece porque "[...] solo existe bajo la forma dinámica de un movimiento político" (Badiou, 2014, p. 15). No existe mayor dolor para el que permanece vivo que no poder enterrar al desaparecido. Según Braunstein (2012), el dolor se magnifica porque no hay posibilidad de duelo, de cierre: el desparecido no es un muerto, es un no-viviente:

Aunque se ensayen miles de explicaciones descriptivas o situacionales casi persuasivas... no hay difunto no hay fallecido no hay detenido NO HAY CUERPO HABIDO DETENIDO NON CORPORA... (Guevara, 1999, p. 39)

\section{Las divergencias simbólicas: compresión y eclosión}

En la construcción de la cadena simbólica hay dos mecanismos formales altamente significantes: la elección del verso y el tono o lenguaje. Nuevamente se producen divergencias notables. Mientras que el poemario de Romualdo expresa una voluntad por restringir al lenguaje, por reducir la expresión al mínimo condensando al máximo la palabra, en el poemario de Guevara la versificación desaparece siguiendo el molde de la prosa y generando ritmo por la duración de la unidad sonoro-gráfica (sílaba) ${ }^{8}$, la puntuación (limitada) y la delimitación lógica de unidades de sentido (fraseo). Esto supone desatar el lenguaje, liberarlo de las restricciones formales convencionales. 
El resultado en ambos casos, aunque divergente, es notable; la diversidad de herramientas y la variedad de aproximaciones produce textos de elevada riqueza verbal. Romualdo refrena los excesos del Canto coral a Túpac Amaru o de Edición extraordinaria, mientras que Guevara mantiene el flujo aluviónico que caracteriza su poesía última ${ }^{9}$. Esta constituye la segunda divergencia importante: el fraseo clásico, de arte menor, del poemario de Romualdo, tributario de la poesía bucólica o cercana a la estética de la chanson, contrasta con el influjo poundiano evidente en Guevara, que mantiene su opción por el poema prosado, dejando de lado el tema de la métrica formal para retornar al corte de verso definido por el ritmo y duración silábica, una opción propuesta por Ezra Pound en los Cantos y pocas veces comentada a pesar del notorio influjo helénico en el conjunto de su obra. Los efectos de ambos tipos de opción musical ${ }^{10}$ transitan entre la reflexión y el aturdimiento. El verso corto en Romualdo, al contrastar con el espacio abierto, contribuye al distanciamiento reflexivo, son golpes intermitentes de sentido con necesidad de costura o unión externa; incrementan el rol del lector al disminuir la autonomía del texto en la construcción del sentido. Ello no quiere dar a entender que el sentido en el poema de Romualdo es oscuro o se encuentra oculto; las claves en cada verso enlazan un sentido sumamente evidente, pero al contrastarse con el procedimiento de Guevara será más simple descifrar su intellectio.

La elección del verso extendido, casi inexistente desde la perspectiva visual pero definido musicalmente en Guevara, funciona como un ametrallamiento constante de la conciencia del lector. Un ritmo acelerado no permite la pausa y condiciona una situación de aturdimiento por acumulación. Esta apertura del lenguaje hacia una liberación de las barreras métricas contrasta, de forma opuesta al procedimiento empleado por Romualdo, con la ambientación en espacios constreñidos, cerrados.

En Romualdo asistimos al universo de lo ya realizado, el universo ejecutivo de lo concluido (el asesinato, la desaparición); en Guevara, al universo actuante, performante, de lo que está en proceso (el encubrimiento, el engaño). Por eso contrastan entre ambos textos un mundo en paz que encierra muertos y un mundo operante que encierra secretos. En ambos casos el componente obsceno 
es evidente en diferente manera. En el texto de Romualdo, la obscenidad radica en el contraste entre apacibles campos y su verdadera naturaleza de ser campos de muerte, en el de Guevara la obscenidad está en el secreto y su naturaleza de conocido-no conocido y la sospecha de su realidad tanto para el encubridor como para el engañado desde lo burocrático-no operativo. Al respecto, Žižek apunta: "Sin embargo, el hecho sigue siendo que la ejecución del holocausto fue tratada por el aparato nazi mismo como una especie de sucio secreto obsceno, no reconocido públicamente, resistiendo una traducción simple y directa a la anónima maquinaria burocrática" (1999, p. 87).

Ambos poemarios comparten el referente de la violencia política desde dos ámbitos que ya definimos como el paisaje del Ande peruano y el de la oficina o dependencia burocrática del Estado. Ello significa que, en términos genéricos, opera la oposición campo-ciudad, y la percepción difiere bajo las condiciones de cada uno de estos ambientes. El tono general del texto de Romualdo es el del lamento, mientras que en el caso de Guevara es el de la denuncia, la protesta ${ }^{11}$ :

No es rocío el que cae y las baña

sino el llanto de las madres

frágiles como la lluvia

corolas de harapos

en un ramo de violencia. (Romualdo, 2005, p. 29)

Cuando un sistema así gobierna a los hombres tarde o temprano más temprano que tarde las llanuras los campos se cubren de cadalsos las playas los desiertos hasta los horizontes se elevan los empalados vivos (Guevara, 1999, p. 38)

En resumen, en "Fragmentos", el escenario es abierto, luminoso y extenso mientras el lenguaje es constreñido. En "Grandes hielos. Las cordilleras", el escenario es cerrado, oscuro; es la oficina, la comisaría, el ámbito donde predomina lo burocrático. Podríamos leer todo texto como una nueva versión 
del momento de acceso a la simbolización; la elección de la estrategia discursiva del texto iría más allá de lo meramente imaginario. Si lo analizamos desde las cinco operaciones de la retórica clásica, inventio, dispositio, elocutio, memoria y actio, revisitadas por Arduini, diríamos que la sexta operación, propuesta por este autor como la superior, a partir de Sulpicio y Agustín (Arduini, 2000, p. 60), la intellectio, es el terreno de las elecciones figurativo-simbólicas y precede a las otras cinco en el tiempo y en la intención comunicativa; en ella se registra la operación de re-presentación, la elección metafórica por excelencia. Según el propio Arduini, la naturaleza del texto, como señalamos anteriormente, se juega al momento de la intellectio.

¿Cuál será la naturaleza elegida para el texto a fin de lograr la representación del mundo, de lo Real? Si lo Real es aquello que no puede ser representado y la metaforización es la forma por excelencia de nominar algo sin presentarlo en el texto, ¿no será la intellectio la metaforización primaria? Cuando vemos la intellectio del texto como la elección formal primordial, su cercanía al campo de la metáfora es innegable. Si la adquisición del lenguaje es el acceso a lo simbólico, la dimensión simbólica en ambos poemas se basa en una adscripción de diversa índole al lenguaje: Romualdo genera sentido por oposición, lo luminoso y abierto se opone a la reconstrucción de lo sórdido u oscuro: la obscenidad del gran Otro copa el universo natural, el campo abierto, las grandes aperturas de horizonte. Guevara construye sentido por adecuación. La obscenidad es cubierta, se escenifica en las catacumbas, vive en lo subterráneo, alejado de la luz del sol. El lenguaje opaco, llano y pulido de "Fragmentos" se opone a la amplitud del escenario; el lenguaje desbordante y excesivo de "Grandes hielos. Las cordilleras", se opone al ambiente cerrado, limitado. Donde Romualdo abre el espacio, Guevara lo encierra; donde Guevara desata el flujo de la lengua, Romualdo lo constriñe. Se dirá que en ambos casos se trata de contrastes violentos, pero mediante ese contraste Romualdo opone el dolor y oscuridad de la muerte a la luminosidad del paisaje andino; Guevara, por el contrario, genera una atmósfera de opresión y oscuridad que se inscribe consistentemente en el campo sémico de la muerte. 


\section{Un retorno breve al goce}

Si tomamos nuevamente el tema del goce en ambos poemarios, se hace imperativa una reflexión adicional: si ambos textos refieren el mismo acontecimiento desde perspectivas distintas definidas por su respectiva intellectio, y sostenemos que ambos, al reconstituir la unidad imaginario-simbólico-real, nos permiten acceder a la dimensión del goce, ¿cómo estos dos caminos diferentes desembocan en el mismo punto?

En apariencia, como sostuvimos anteriormente, operan en momentos distintos del acontecimiento. El de Romualdo, en un tiempo posterior; el de Guevara, en la performancia, la ocurrencia del acontecimiento. El tiempo del texto de Romualdo es el del eterno retorno: lo imaginario nos hace conocer que detrás de la naturaleza apacible, detrás de lo que oculta la huella de la incisión, existe el corte aunque no se vea la cicatriz. Nos retrotrae, nos toca el hombro desde atrás para hacernos volver la mirada, mientras que el texto de Guevara nos instala en un presente eterno y kafkiano, sin salida. No nos hace "regresar" al momento del acontecimiento porque siempre estaremos ahí. Según Romualdo, siempre regresaremos aunque no lo deseemos, y esto refuerza el concepto del goce como instancia pulsional, inexplicable. Volvemos a lo que no queremos volver en parte porque el texto nos hace volver por su cualidad de logro literario, en esto radica su anclaje en el sinsentido (lo Real) en contraposición al acercamiento de interpretación convencional de textos que hurga en el sentido como mecanismo central, siguiendo la lectura lacaniana (Ubilluz, 2017, p. 17).

La riqueza de la poesía como herramienta de conocimiento se hace evidente en el cruce de estos dos poemarios. En la lectura consecutiva de ambos textos encontramos una interesante veta de reflexión que hermana la lectura lacaniana con la herramienta retórica contemporánea; es interesante notar cómo lo simbólico y lo imaginario pueden ser divergentes en lo Imaginario (recordemos con Lacan que toda lectura de este choque es, finalmente, imaginario, si es que no insertamos lo Real), pero se hermanan en su alusión a lo Real (Žižek, 2008), al horror de la muerte, al doble horror de la muerte violenta. 


\section{Notas}

1 De $A$ los ataúdes, a los ataúdes, se analiza lo que corresponde al grupo de poemas denominados "Grandes hielos. Las Cordilleras" y de Ni pan ni circo corresponde "Fragmentos".

2 "Cinismo es la falsa conciencia ilustrada. Es la conciencia modernizada y desgraciada, aquella en la que la Ilustración ha trabajado al mismo tiempo pero ni la ha consumado ni puede siquiera consumarla. En buena posición y miserable al mismo tiempo, esta conciencia ya no se siente afectada por ninguna otra crítica de la ideología, su falsedad está reflexivamente amortiguada" (Sloterdijk, 2011, pp. 40-41).

3 Al respecto señala Arduini: "[...] esta [la intellectio] es la operación que encamina y dirige el proceso retórico estructurando el modelo de mundo compartible por orador y destinatario" (2000, p. 46).

4 Subrayado nuestro.

5 Resaltamos la definición de goce diferenciada de placer que incluye el dolor, la rabia, lo pulsional y reiterativo sinsentido.

6 Podría precisarse que el yo poético que construye Romualdo es ese mismo doliente, pero el dolor que se lee en los poemas de "Fragmentos" es universal, es de todos, es de los otros y del sujeto que recrea la historia, el poeta que es tratado como mediador fantasmal que hace posible el enfrentamiento a lo real mediante el plus de goce del placer estético.

7 Y quizá de alguien más que el Otro. Según Žižek, “[...] la mirada del observador inocente es también en cierto modo inexistente, pues se trata de la mirada neutral imposible de alguien que se exenta falsamente de su existencia histórica concreta" (1999, pp. 25-26).

8 Diríase que Guevara, a lo Pound, genera un ritmo sobre la base de la duración del sonido, siguiendo el molde clásico (yámbico, trocaico, etc.).

9 Hotel del Cuzco (1972) y los poemarios anteriores difieren del flujo aparentemente descontrolado del lenguaje de Guevara. Es llamativo que en el caso de Romualdo el exceso verbal se vea como defecto (por grandilocuencia) y en Guevara constituya su savoir faire.

10 En última instancia, toda elección de longitud de verso y de puntuación debería ser musical, además de obedecer a la construcción del sentido en el texto.

11 Otro caso más de convergencia con Pound, gran modelo de Guevara. El poeta es la conciencia de la autoridad, se enfrenta al poder cuestionando su actuación. En los Cantos, se encuentran muchos poemas de tono recriminatorio u orientados a proponer, mediante la crítica, cómo gobernar con justicia. También, ciertamente, presenta ejemplos de gobernantes justos.

\section{Referencias bibliográficas}

Arduini, S. (2000). Prolegómenos a una teoría general de las figuras. Murcia: Universidad de Murcia. 
Badiou, A. (2014). Veinticuatro notas sobre los usos de la palabra 'pueblo'. En A. Badiou, et al. ¿Qué es un pueblo? (pp.9-19). Buenos Aires. Eterna Cadencia.

Braunstein, N. (2012). La memoria del uno y la memoria del otro. Ciudad de México: Siglo Veintiuno Editores.

Edelstein, N., et al. (productores) \& Lynch, D. (director). (2001). Mulholland drive [cinta cinematográfica]. Francia- Estados Unidos: Les Films Alain Sarde, Asymmetrical Productions, Babbo Inc., Canal+, The Picture Factory.

Guevara. P. (1972). Hotel del Cuzco y otras provincias del Perú. Lima: Instituto Nacional de Cultura.

Guevara, P. (1999). A los ataúdes, a los ataúdes. Lima: Ediciones COPÉ.

Grimaldi, A. (productor) \& Pasolini, P.P. (director). (1975). Saló o los 120 días de Sodoma [cinta cinematográfica]. Italia, Francia: Produzioni Europee Associate, Les Productions Artistes Associés.

Higgins, J. (2006). Historia de la literatura peruana. Lima: Fondo Editorial de la Universidad Ricardo Palma.

Jakobson, R. (1981). Ensayos de lingüística general. Barcelona: Seix Barral.

Jameson, F. (1977). Imaginary and Symbolic in Lacan: Marxism, Psychoanalytic Criticism, and the Problem of the Subject. Yale French Studies, 55/56, [Literature and Psychoanalysis. The Question of Reading: Otherwise], 338-395.

Romualdo, A. (2005). Ni pan ni circo. Lima: Instituto Nacional de Cultura.

Sloterdijk, P. (2011). Crítica de la razón cínica, 5. a ed. Madrid: Ediciones Siruela.

Ubilluz, J. C. (2017). La venganza del indio. Ciudad de México: Fondo de Cultura Económica.

Žižek, S. (1999). El acoso de las fantasías. Ciudad de México: Siglo Veintiuno Editores.

Žižek, S. (2008). Cómo leer a Lacan. Buenos Aires: Paidós. 